\title{
ENVIRONMENTAL IMPACT ASSESSMENT USING A WEIGHTED GLOBAL INDEX: A METHODOLOGICAL PROPOSAL
}

\author{
ADMILSON ÍRIO RIBEIRO $^{1}$, ADRIANO BRESSANE ${ }^{2}$, FELIPE HASHIMOTO FENGLER ${ }^{1}$, \\ REGINA MÁRCIA LONGO ${ }^{3}$, ALESSANDRA LEITE DA SILVA ${ }^{3}$, JOSE ARNALDO F. ROVEDA ${ }^{1}$, \\ MARCUS VINÍCIUS RIBEIRO ${ }^{2} \&$ GERSON ARAÚJO DE MEDEIROS ${ }^{1}$ \\ ${ }^{1}$ Universidade Estadual Paulista (UNESP), Brazil \\ ${ }^{2}$ Faculdade de Engenharia de Sorocaba (FACENS), Brazil \\ ${ }^{3}$ Pontifícia Universidade Católica de Campinas (PUCC), Brazil
}

\begin{abstract}
Activities considered effectively or potentially polluting depend on an environmental impact assessment before starting their installation and operations. However, the lack of a structured logical procedure for supporting decision-making may compromise the comparative analysis of alternatives available. In this paper we present a methodological proposal based on a weighted global index $\left(i g i_{w}\right)$ for comparative analysis in environmental impact assessments. For that, the impact global index (igi), originally developed by Bressane et al., was improved taking into account an additional weighting based on the prioritization of impacts according to their relative importance case-by-case. Then, the new index was used on two case studies. In the first one, the $i g i_{w}$ was applied to support decisionmaking on maintenance or demolishing of the buildings in situation of irregularity. Secondly, several technologies and siting alternatives have been compared for installing a sewage treatment plant into an urban condominium. As a result, it was found that the weighted impact global index was able to critically and comprehensively evaluate the alternatives available for both cases under study. In conclusion the $i g i_{w}$ may be considered a promising approach as a method for supporting decisionmaking in environmental impact assessments.
\end{abstract}

Keywords: global index, project alternatives, environmental assessment.

\section{INTRODUCTION}

Environmental impacts assessment has become indispensable to support decisions with regard to the viability of activities in sustainable patterns [1]. Activities considered effectively or potentially polluting are conditioned to the previous analysis, taking into account the comparative analysis of the project alternatives [2].

Several techniques have been developed, among which the spontaneous techniques (Ad hoc methods), listing (Batelle method), matrices (Leopold methods), networks of interactions (IMPACT method), simulation (KSIM method), and maps overlay (McHarg method). On the other hand, such methods have been developed with specific goals, and oftentimes require adaptations to be useful for different purposes.

Environmental guidelines recommend analyses for predicting the magnitude and importance of the impacts, notwithstanding there is no standardization with regard to the treatment of the influence variables.

In this present paper, we propose a weighted impact global index $\left(i g i_{w}\right)$, which results from an improvement of the original index (igi) proposed by Bressane et al. [3], taking into account an additional weighting based on the prioritization of impact according to its relative importance case-by-case. Then, the new index was applied in two case studies. In the first one, the $i g i_{w}$ was applied to support decision-making on maintenance or demolishing of the buildings in situation of irregularity. Secondly, several technologies and siting alternatives has been compared for installing a sewage treatment plant. 


\section{MATERIAL AND METHOD}

\subsection{Study areas}

In the first case, the $i g i_{w}$ was applied for assessing a parking lot of a commercial establishment, located in the Guarulhos city, São Paulo State, Brazil, which made intervention in an environmental protection area and, hence, to support decision-making on its maintenance or demolishing.

After evaluating the environmental conditions, such as climate and hydrological issues [5]-[7], pedological, geomorphological and geological situation [8], [9], as well as the fauna and flora [10], in the area and its surroundings, a predicting of potential impacts was made. In doing this, environmental impacts were identified on the: water pollution, geological stability, soil degradation, biodiversity loss, gene flow, visual pollution, and sanitary conditions [3].

In the second case study, project alternatives were evaluated for installing a sewage treatment plant into an urban condominium, located in the Mairinque city, São Paulo State, Brazil, in the transition zone of the Biosphere Reserve of São Paulo city, where a more intensive, but non-destructive, use of the soil is allowed. A more detailed characterization of this second study area can be viewed in Bressane et al. [4]. Thus, the following environmental impacts were predicted: generation of employment and income with improved standard of living, suppression of flora and fauna with biodiversity loss, improvement of health conditions of the population's health and well-being, erosion and generation of effluents and wastes with water and soil pollution, generation of noise with noise pollution, generation of gases with air pollution, and odour generation with damages to the well-being of the population.

\subsection{Methodological proposal}

The original Impact Global Index (igi) was proposed by Bressane et al. [3] as a systematization of mathematical operations addressing Magnitude $(\mu)$ and Importance $(1)$ weights, whose equation results in Significance $(\sigma)$ of impact. Thus, the igi provides a single value that allows direct comparisons between scenarios and project alternatives.

As aforementioned, two possible applications are: (1) a comparative evaluation of environmental impacts resulting from the maintenance and demolishing of irregular activities, and (2) an integrated evaluation for supporting the selection of project alternatives, prior to the implementation of activities, i.e. to compare different combinations of technological and sitting alternatives.

The original index was modelled considering the duration, extension and intensity as indicators of impact magnitude and, in turn, the accumulation, reversibility and sensitivity as indicators of impact importance [3], as shown in Table 1.

From the above, while the indicators $\left(p_{j}\right)$ quantify the magnitude $(\mu)$ and importance $(\iota)$ of the impact, the modifiers $\left(m_{k j}\right)$ correspond to the classes that characterize the condition evaluated for each criterion, according to the weights assigned $\left(w_{k j}\right)$.

The values assigned to such weights have been defined so as to limit a suitable range for the $i g i$ between $(-1,1)$, and thus facilitate a comparative evaluation of the project alternatives. Considering that the impacts may be positive (beneficial) or negative (harmful), the lower $(-1)$ and upper (1) thresholds represent the worst and the best project alternatives, respectively, evaluated according to eqns (1)-(7): 
Table 1: Criteria and indicators of the Global Impact Index (igi). (Source: Modified from Bressane et al. [3].)

\begin{tabular}{|c|c|c|c|}
\hline Criteria & Indicators $\left(p_{j}\right)$ & Modifier $\left(m_{k j}\right)$ & Weight $\left(w_{k j}\right)$ \\
\hline \multirow{9}{*}{ 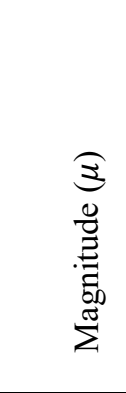 } & \multirow{3}{*}{$\begin{array}{l}\text { Duration }\left(p_{1}\right) \text { : } \\
\text { residence time of the impact }\end{array}$} & short to medium $\left(m_{11}\right)$ & $1 / 9\left(w_{11}\right)$ \\
\hline & & long-term $\left(m_{21}\right)$ & $2 / 9\left(w_{21}\right)$ \\
\hline & & permanent $\left(m_{31}\right)$ & $3 / 9\left(w_{31}\right)$ \\
\hline & \multirow{3}{*}{$\begin{array}{l}\text { Extension }\left(p_{2}\right) \text { : } \\
\text { spatial comprehensiveness } \\
\text { of the impact }\end{array}$} & punctual $\left(m_{12}\right)$ & $1 / 9\left(w_{12}\right)$ \\
\hline & & local $\left(m_{22}\right)$ & $2 / 9\left(w_{22}\right)$ \\
\hline & & regional $\left(m_{32}\right)$ & $3 / 9\left(w_{32}\right)$ \\
\hline & \multirow{3}{*}{$\begin{array}{l}\text { Intensity }\left(p_{3}\right) \text { : } \\
\text { degree of modification of } \\
\text { environmental attributes }\end{array}$} & low $\left(m_{13}\right)$ & $1 / 9\left(w_{13}\right)$ \\
\hline & & medium $\left(m_{23}\right)$ & $2 / 9\left(w_{23}\right)$ \\
\hline & & $\operatorname{high}\left(m_{33}\right)$ & $3 / 9\left(w_{33}\right)$ \\
\hline \multirow{9}{*}{ 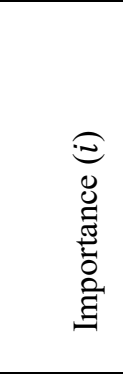 } & \multirow{3}{*}{$\begin{array}{l}\text { Accumulation }\left(p_{4}\right) \text { : } \\
\text { improvement or worsening } \\
\text { of the changes }\end{array}$} & absent $\left(m_{44}\right)$ & $0 / 9\left(w_{44}\right)$ \\
\hline & & uncertain $\left(m_{54}\right)$ & $2 / 9\left(w_{54}\right)$ \\
\hline & & present $\left(m_{64}\right)$ & $3 / 9\left(w_{64}\right)$ \\
\hline & \multirow{3}{*}{$\begin{array}{l}\text { Reversibility }\left(p_{5}\right) \text { : } \\
\text { capability to return to a pre- } \\
\text { disturbance situation }\end{array}$} & yes $\left(m_{45}\right)$ & $1 / 9\left(w_{45}\right)$ \\
\hline & & maybe $\left(m_{55}\right)$ & $2 / 9\left(w_{55}\right)$ \\
\hline & & no $\left(m_{56}\right)$ & $3 / 9\left(w_{65}\right)$ \\
\hline & \multirow{3}{*}{$\begin{array}{l}\text { Sensitivity }\left(p_{6}\right) \text { : } \\
\text { tolerance to changes in } \\
\text { environmental attributes }\end{array}$} & null $\left(m_{46}\right)$ & $0\left(w_{46}\right)$ \\
\hline & & partial $\left(m_{56}\right)$ & $2 / 9\left(w_{56}\right)$ \\
\hline & & total $\left(m_{66}\right)$ & $3 / 9\left(w_{66}\right)$ \\
\hline
\end{tabular}

where, igi - impact global index; $i$ - impact $(1,2, \ldots, n) ; n$ - total number of impacts; $\sigma_{i}-$ significance of the $i$-th impact, and

$$
\sigma_{i}=\mu_{i} \cdot \iota_{i},
$$

with $\mu_{i}$ - magnitude of impact $i, \iota_{i}$ - importance of the $i$-th impact, and

$$
\mu_{i}=\sum_{j=1}^{3}\left(p_{j}\right)_{i}
$$

and

$$
\iota_{i}=\sum_{j=4}^{6}\left(p_{j}\right)_{i},
$$

with $\left(p_{j}\right)_{i}$ - value of the $j$-th indicator for the $i$-th impact, and for the magnitude,

$$
\left(p_{j}\right)_{i}=\sum_{k=1}^{3}\left(w_{k j} \cdot m_{k j}\right)_{i}
$$

and for the importance 


$$
\left(p_{j}\right)_{i}=\sum_{k=4}^{6}\left(w_{k j} \cdot m_{k j}\right)_{i}
$$

with $\left(w_{k j}\right)_{i}$ - weight of the modifier $k$ belonging to the $j$-th indicator for the $i$-th impact, according to the values proposed in Table $2,\left(m_{k j}\right)_{i}$ - value of the modifier $k$ belonging to the $j$-th indicator for the $i$-th impact, which represents the condition evaluated for impact according to each weight, given by:

$$
\left(m_{k j}\right)_{i}=\left\{\begin{array}{c}
1, \text { if it belongs to the evaluated condition } \\
-1, \text { if the magnitude of the impact is harmful } \\
0, \text { otherwise. }
\end{array}\right.
$$

Taking into account these definitions and eqns (8) and (9):

$$
\mathbf{M}=\left[\begin{array}{llll}
\mu_{1} & \mu_{2} & \ldots & \mu_{n}
\end{array}\right]
$$

and

$$
\mathbf{I}=\left[\begin{array}{llll}
l_{1} & \iota_{2} & \ldots & \iota_{n}
\end{array}\right]
$$

where $\mathbf{M}$ - magnitude vector of impacts, I - importance vector of impacts, so that the igi can be calculated by eqn (10):

$$
i g i=\frac{1}{n} \sum_{i=1}^{n} \sigma_{i}=\frac{1}{n} \sum_{i=1}^{n} \mathrm{M}_{i} \mathrm{I}_{i}=\frac{1}{n}\left(\mathbf{M} . \mathbf{I}^{\mathrm{T}}\right) .
$$

Considering a comparative analysis between two or more project alternatives, the igi for each one can be obtained according to eqn (11):

$$
\operatorname{igi}_{\lambda \tau}=\left(\frac{1}{n} \sum_{i=1}^{n}\left(\sigma_{i}\right)_{\lambda \tau}\right)=\left(\frac{1}{n} \sum_{i=1}^{\mathrm{n}}\left(\mathbf{M}_{i \lambda \tau} . \mathbf{I}_{i \lambda \tau}\right)\right),
$$

where $i g i_{\lambda \tau}$ - impact global index of project alternative $\left(A_{\lambda \tau}\right)$ composed by the technology $\tau$ associated with the location $\lambda$, with $\lambda=(1,2, \ldots, l)$, where $l$ is the total number of sitting alternatives assessed, and $\tau=(1,2, \ldots, t)$, where $t$ is the total number of alternative technologies assessed. Therefore, for the purpose of organizing the data, we have the vector given in eqn (12):

$$
\boldsymbol{I} \boldsymbol{G} \boldsymbol{I}=\delta_{\lambda \tau}\left(\frac{1}{n}\left(\mathbf{M}_{\lambda \tau} \cdot\left[\mathbf{I}_{\lambda \tau}\right]^{\mathrm{T}}\right)\right)=\left[i g i_{11} i g i_{12} \ldots i g i_{l t}\right]
$$

where IGI - matrix composed of the impact global indices of each scenario evaluated; and $\delta_{\lambda \tau}-$ Dirac delta function defined as eqn (13):

$$
\delta_{\lambda \tau}=\left\{\begin{array}{l}
1, \text { if } \lambda=\tau \\
0, \text { otherwise. }
\end{array}\right.
$$

Thus, the best project alternative $\left(A_{\lambda / \tau}\right)$ among the evaluated ones will be the one with the highest igi (more positive or less negative impacts), given by eqn (14):

$$
A_{\lambda \prime \tau \prime}=\max (\boldsymbol{I} \boldsymbol{G I}) \text {, }
$$

where $\lambda^{\prime}$ - the best sitting alternative (less sensitive to impacts by $\tau^{\prime}$ ), $\tau^{\prime}$ - the best technological alternative (less severe in the generation of impacts on $\lambda^{\prime}$ ). 
Table 2: Prioritization of environmental impacts $\left(i_{i}\right)$ in the selection of project alternatives, in which water pollution $\left(i_{1}\right)$, geological stability $\left(i_{2}\right)$, soil degradation $\left(\mathrm{Si}_{3}\right)$, biodiversity loss $\left(i_{4}\right)$, gene flow $\left(i_{5}\right)$, visual pollution $\left(i_{7}\right)$, and sanitary conditions $\left(i_{7}\right)$.

\begin{tabular}{|c|c|c|c|c|c|c|c|c|c|c|}
\hline & $i_{1}$ & $i_{2}$ & $i_{3}$ & $i_{4}$ & $i_{5}$ & $i_{6}$ & $i_{7}$ & $\begin{array}{c}\text { Eigenvalue } \\
(\lambda)\end{array}$ & $\begin{array}{l}\text { Eigenvector } \\
\qquad\left(\boldsymbol{v}_{\boldsymbol{i}}\right)\end{array}$ & $R_{\mathrm{C}}$ \\
\hline$i_{1}$ & 1 & 3 & 2 & $1 / 2$ & $1 / 2$ & 5 & 1 & 7.28 & 0.167 & \multirow{7}{*}{0.04} \\
\hline$i_{2}$ & & 1 & 1 & $1 / 3$ & $1 / 3$ & 3 & $1 / 2$ & 7.22 & 0.082 & \\
\hline$i_{3}$ & & & 1 & $1 / 2$ & $1 / 2$ & 3 & $1 / 2$ & 7.29 & 0.094 & \\
\hline$i_{4}$ & & & & 1 & 1 & 5 & $1 / 2$ & 7.47 & 0.197 & \\
\hline$i_{5}$ & & & & & 1 & 5 & $1 / 2$ & 7.47 & 0.197 & \\
\hline$i_{6}$ & & & & & & 1 & $1 / 3$ & 7.25 & 0.039 & \\
\hline$i_{7}$ & & & & & & & 1 & 7.40 & 0.223 & \\
\hline
\end{tabular}

For developing the weighted impact global index $\left(i g i_{w}\right)$, from the original index $(i g i)$ introduced by Bressane et al. [3], weights of the prioritization were obtained by using the analytic hierarchy process (AHP) method, proposed by Saaty [11].

The AHP method considers a relative importance scale with values ranging from 1 (equivalent importance) to 9 (extreme importance), whose application results in a pairwise comparison matrix $(\boldsymbol{A})$. From this matrix, the importance of each environmental impact is expressed as a vector $(\boldsymbol{v})$, associated with the maximum eigenvalue $\left(\lambda_{\max }\right)$, obtained using eqn (15):

$$
\operatorname{det}\left(\boldsymbol{A}-\lambda_{\max } I\right)=0 .
$$

After determining $\lambda_{\max }, v$ is determined as the eigenvector that solves eqn (16):

$$
\lambda_{\max } v=\boldsymbol{A v} \text {. }
$$

Then, the environmental impacts prioritization is validated when the consistency ratio $\left(R_{\mathrm{C}}\right)$ is less than or equal to 0.1 (eqn (17)):

$$
R_{C}=C_{i} / R_{i}
$$

in which $R_{i}$ is a tabulated value according to the dimension of the matrix, and $C_{i}$ is the consistency index, given by eqn (18):

$$
C_{I}=\left(\lambda_{\max }-n\right) /(n-1) \text {. }
$$

After all, the new impact global index $\left(i g i_{W}\right)$ is obtained by means of a weighted linear combination given by eqn (19):

$$
i g i_{w}=\frac{1}{n} \sum_{i=1}^{n} v_{i} \cdot \sigma_{i}=\frac{1}{n} \sum_{i=1}^{n} v_{i} \cdot \mu_{i} \cdot \iota_{i}
$$

in which $v_{i}$ is the weight of $i$-th impact according its prioritization with AHP method. 


\section{RESULTS AND DISCUSSION}

\subsection{Environmental impacts weighting based on prioritization with AHP}

The pairwise comparisons between environmental impacts assessed by experts in both cases under study are presented in Tables 2 and 3. In the first case, it can be seen that the sanitary conditions were evaluated as more important than other environmental impacts $\left(\boldsymbol{v}_{\boldsymbol{i}}=0.223\right)$. Biodiversity loss and gene flow commitment achieved the second greater prioritization $\left(\boldsymbol{v}_{\boldsymbol{i}}=\right.$ 0.197).

In turn, in the second case, the experts considered the loss of biodiversity, as the more important environmental impact, with higher weight of prioritization $\left(\boldsymbol{v}_{\boldsymbol{i}}=0.290\right)$. Analysing both cases under study, one can note that the same environmental impact (biodiversity loss) may be considered the most important impact in a case, but the second more important in other case. This highlights the flexibility provided by the $i g i_{w}$ for analysis case-by-case, in comparison with the original index (igi).

\subsection{Decision-making on maintenance and demolishing of an irregular activity}

Taking into account the environmental impacts predicted in a prior stage, scores has been attributed by experts for both scenarios, correspondent to the maintenance $(m)$ and the demolishing $(d)$ of irregular activity under analysis. Therefore, as in both scenarios the location is the same $(\lambda)$, the alternatives can be identified simply by $A_{m}$ (maintenance, i.e. $\lambda 1=m$ ), and by $A_{d}$ (demolishing, i.e., $\lambda 2=d$ ). As a result from these scoring, Tables $4-7$ were obtained.

From the presented scores, the $\boldsymbol{I G I}_{\boldsymbol{w}}$ results in $\boldsymbol{I G I}_{\boldsymbol{w}}=\left[\mathrm{igi}_{w_{\lambda 1}} i g i_{w_{\lambda 2}}\right]=\left[\operatorname{igi}_{w_{m^{\prime}}} i g i_{w_{d}}\right]=$ $[0.010,0.002]$, hence, we have that the best alternative for the case under study correspond to $A_{\lambda / \tau^{\prime}}=\max \left(\boldsymbol{I G} \boldsymbol{I}_{\boldsymbol{w}}\right)=\left[i g i_{w}\right]_{m}=[0.010]=A_{m}$, i.e, the maintenance scenario.

Table 3: Prioritization of environmental impacts $\left(i_{i}\right)$ in the irregular activity assessment, in which generation of employment $\left(i_{1}\right)$, biodiversity loss $\left(i_{2}\right)$, improvement of health conditions $\left(i_{3}\right)$, water and soil pollution $\left(i_{4}\right)$, noise pollution $\left(i_{5}\right)$, air pollution $\left(i_{6}\right)$, and odour generation $\left(i_{7}\right)$.

\begin{tabular}{|c|c|c|c|c|c|c|c|c|c|c|}
\hline & $i_{1}$ & $i_{2}$ & $i_{3}$ & $i_{4}$ & $i_{5}$ & $i_{6}$ & $i_{7}$ & $\begin{array}{l}\text { Eigenvalue } \\
(\lambda)\end{array}$ & $\begin{array}{l}\text { Eigenvector } \\
\left(\boldsymbol{v}_{\boldsymbol{i}}\right)\end{array}$ & $\mathrm{R}_{\mathrm{C}}$ \\
\hline$i_{1}$ & 1 & $1 / 3$ & $1 / 2$ & $1 / 2$ & 3 & $1 / 3$ & 2 & 7.63 & 0.100 & \multirow{7}{*}{0.06} \\
\hline$\overline{i_{2}}$ & & 1 & 2 & 3 & 3 & 2 & 5 & 7.53 & 0.290 & \\
\hline$i_{3}$ & & & 1 & 2 & 1 & 1 & 3 & 7.59 & 0.158 & \\
\hline$i_{4}$ & & & & 1 & 3 & 1 & 5 & 7.58 & 0.156 & \\
\hline$i_{5}$ & & & & & 1 & $1 / 2$ & 3 & 7.20 & 0.089 & \\
\hline$i_{6}$ & & & & & & 1 & 3 & 7.56 & 0.163 & \\
\hline$i_{7}$ & & & & & & & 1 & 7.30 & 0.044 & \\
\hline
\end{tabular}


Table 4: Impacts magnitude analysis for the maintenance scenarios $\left(A_{m}\right)$. (Source: Modified from Bressane et al. [3].)

\begin{tabular}{|c|c|c|c|c|c|c|c|c|c|}
\hline \multicolumn{3}{|c|}{ Analysis parameters } & \multicolumn{7}{|c|}{ Evaluated condition } \\
\hline$p_{j}$ & $m_{k j}$ & $w_{k j}$ & $i_{1}$ & $i_{2}$ & $i_{3}$ & $i_{4}$ & $i_{5}$ & $i_{6}$ & $i_{7}$ \\
\hline $\begin{array}{l}\bar{\vdots} \\
\stackrel{\Xi}{\Xi} \\
\vdots \\
\Xi\end{array}$ & 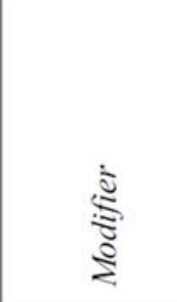 & $\begin{array}{l}\frac{\overline{5}}{20} \\
=\end{array}$ & 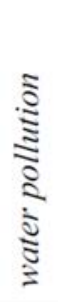 & 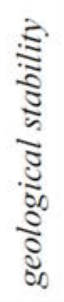 & 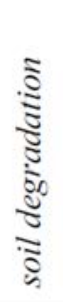 & $\begin{array}{l}\hat{\hat{3}} \\
\vdots \\
\vdots \\
\vdots \\
\vdots \\
\vdots \\
\vdots \\
\vdots\end{array}$ & $\frac{\grave{D}}{\stackrel{5}{5}}$ & 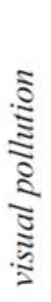 & 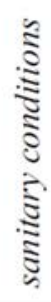 \\
\hline \multirow{3}{*}{ Duration $\left(p_{l}\right)$} & Short term & $1 / 9$ & 0 & 0 & 0 & 0 & 0 & 0 & 0 \\
\hline & Long term & $2 / 9$ & 0 & 0 & 0 & 0 & 0 & 0 & 0 \\
\hline & Permanent & $3 / 9$ & +1 & +1 & +1 & -1 & -1 & -1 & +1 \\
\hline \multirow{3}{*}{ Extension $\left(p_{2}\right)$} & Ponctual & $1 / 9$ & 0 & 0 & 0 & 0 & 0 & 0 & 0 \\
\hline & Local & $2 / 9$ & 0 & +1 & +1 & -1 & -1 & -1 & +1 \\
\hline & Regional & $3 / 9$ & +1 & 0 & 0 & 0 & 0 & 0 & 0 \\
\hline \multirow{3}{*}{ Intensity $\left(p_{3}\right)$} & Low & $1 / 9$ & +1 & 0 & 0 & -1 & -1 & -1 & 0 \\
\hline & Medium & $2 / 9$ & 0 & 0 & +1 & 0 & 0 & 0 & 0 \\
\hline & High & $3 / 9$ & 0 & +1 & 0 & 0 & 0 & 0 & +1 \\
\hline
\end{tabular}

Table 5: Impacts magnitude analysis for the demolishing scenarios $\left(A_{d}\right)$. (Source: Modified from Bressane et al. [3].)

\begin{tabular}{|c|c|c|c|c|c|c|c|c|c|}
\hline \multicolumn{3}{|c|}{ Analysis parameters } & \multicolumn{7}{|c|}{ Evaluated condition } \\
\hline$p_{j}$ & $m_{k j}$ & $w_{k j}$ & $i_{1}$ & $i_{2}$ & $i_{3}$ & $i_{4}$ & $i_{5}$ & $i_{6}$ & $i_{7}$ \\
\hline 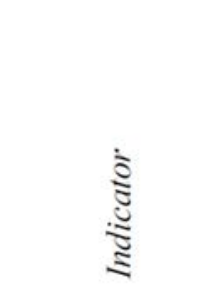 & $\stackrel{\grave{\Xi}}{\stackrel{\Xi}{\Xi}}$ & 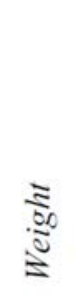 & $\begin{array}{l}\bar{\Xi} \\
\vdots \\
\vdots \\
\vdots \\
\vdots \\
\vdots \\
\vdots\end{array}$ & 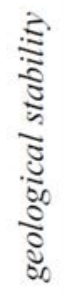 & 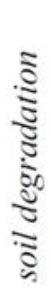 & $\begin{array}{l}\tilde{b} \\
\vdots \\
\vdots \\
\vdots \\
\vdots \\
\vdots \\
\vdots\end{array}$ & $\frac{\hat{े}}{\stackrel{5}{\Xi}}$ & $\begin{array}{l}\vdots \\
\vdots \\
\vdots \\
\vdots \\
\vdots \\
\vdots \\
\vdots\end{array}$ & 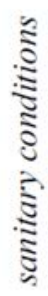 \\
\hline \multirow{3}{*}{ Duration $\left(p_{1}\right)$} & Short term & $1 / 9$ & -1 & 0 & -1 & 0 & 0 & 0 & 0 \\
\hline & Long term & $2 / 9$ & 0 & 0 & 0 & 0 & 0 & 0 & 0 \\
\hline & Permanent & $3 / 9$ & 0 & +1 & 0 & +1 & +1 & +1 & -1 \\
\hline \multirow{3}{*}{ Extension $\left(p_{2}\right)$} & Ponctual & $1 / 9$ & 0 & 0 & -1 & 0 & 0 & 0 & 0 \\
\hline & Local & $2 / 9$ & -1 & +1 & 0 & +1 & +1 & +1 & -1 \\
\hline & Regional & $3 / 9$ & 0 & 0 & 0 & 0 & 0 & 0 & 0 \\
\hline \multirow{3}{*}{ Intensity $\left(p_{3}\right)$} & Low & $1 / 9$ & 0 & 0 & -1 & 0 & 0 & +1 & 0 \\
\hline & Medium & $2 / 9$ & 0 & +1 & 0 & 0 & +1 & 0 & 0 \\
\hline & High & $3 / 9$ & -1 & 0 & 0 & +1 & 0 & 0 & -1 \\
\hline
\end{tabular}


Table 6: Impacts importance analysis for the maintenance scenarios $\left(\mathrm{A}_{\mathrm{m}}\right)$. (Source: Modified from Bressane et al. [3].)

\begin{tabular}{|c|c|c|c|c|c|c|c|c|c|}
\hline \multicolumn{3}{|c|}{ Analysis parameters } & \multicolumn{7}{|c|}{ Evaluated condition } \\
\hline$p_{j}$ & $m_{k j}$ & $w_{k j}$ & $i_{1}$ & $i_{2}$ & $i_{3}$ & $i_{4}$ & $i_{5}$ & $i_{6}$ & $i_{7}$ \\
\hline $\begin{array}{l}\grave{\Xi} \\
\stackrel{\Xi}{\Xi} \\
\Xi\end{array}$ & $\stackrel{\grave{\Xi}}{\stackrel{\Xi}{\Xi}}$ & $\begin{array}{l}\stackrel{\overline{50}}{2} \\
\stackrel{3}{2}\end{array}$ & $\begin{array}{l}\bar{\Xi} \\
\mathbf{\Xi} \\
\vdots \\
\vdots \\
\vdots \\
\vdots \\
\vdots \\
\vdots\end{array}$ & 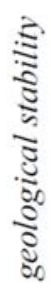 & 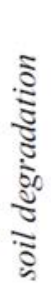 & 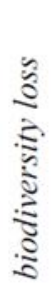 & 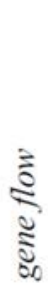 & 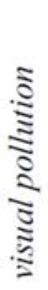 & 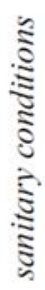 \\
\hline \multirow{3}{*}{ Accumulation $\left(p_{4}\right)$} & Absent & 0 & 1 & 1 & 0 & 0 & 1 & 0 & 0 \\
\hline & Uncertain & $2 / 9$ & 0 & 0 & 1 & 1 & 0 & 1 & 1 \\
\hline & Present & $3 / 9$ & 0 & 0 & 0 & 0 & 0 & 0 & 0 \\
\hline \multirow{3}{*}{ Reversibility $\left(p_{5}\right)$} & Yes & $1 / 9$ & 1 & 1 & 0 & 0 & 0 & 0 & 0 \\
\hline & Maybe & $2 / 9$ & 0 & 0 & 0 & 0 & 0 & 0 & 1 \\
\hline & $\mathrm{No}$ & $3 / 9$ & 0 & 0 & 1 & 1 & 1 & 1 & 0 \\
\hline \multirow{3}{*}{ Sensitivity $\left(p_{6}\right)$} & Null & 0 & 0 & 1 & 0 & 0 & 0 & 0 & 0 \\
\hline & Partial & $2 / 9$ & 1 & 0 & 1 & 1 & 1 & 1 & 0 \\
\hline & Total & $3 / 9$ & 0 & 0 & 0 & 0 & 0 & 0 & 1 \\
\hline
\end{tabular}

Table 7: Impacts importance analysis for the demolishing scenarios $\left(A_{d}\right)$. (Source: Modified from Bressane et al. [3].)

\begin{tabular}{|c|c|c|c|c|c|c|c|c|c|}
\hline \multicolumn{3}{|c|}{ Analysis parameters } & \multicolumn{7}{|c|}{ Evaluated condition } \\
\hline$p_{j}$ & $m_{k j}$ & $w_{k j}$ & $i_{1}$ & $i_{2}$ & $i_{3}$ & $i_{4}$ & $i_{5}$ & $i_{6}$ & $i_{7}$ \\
\hline 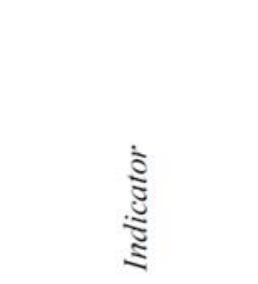 & 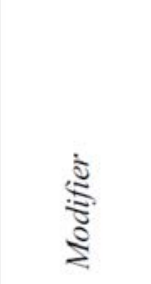 & $\begin{array}{l}\frac{\pi}{50} \\
\stackrel{.0}{0}\end{array}$ & 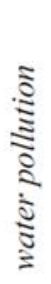 & 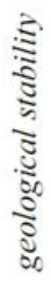 & 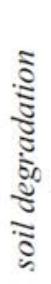 & \begin{tabular}{l}
$\hat{\jmath}$ \\
\multirow{3}{\vdots}{} \\
$\vdots$ \\
$\vdots$ \\
$\vdots$ \\
$\vdots$
\end{tabular} & $\frac{\grave{5}}{\frac{5}{5}}$ & 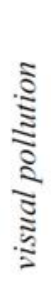 & 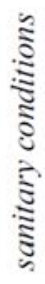 \\
\hline \multirow{3}{*}{ Accumulation $\left(p_{4}\right)$} & Absent & 0 & 0 & 0 & 0 & 0 & 0 & 0 & 0 \\
\hline & Uncertain & $2 / 9$ & 0 & 1 & 0 & 0 & 0 & 1 & 1 \\
\hline & Present & $3 / 9$ & 1 & 0 & 1 & 1 & 1 & 0 & 0 \\
\hline \multirow{3}{*}{ Reversibility $\left(p_{5}\right)$} & Yes & $1 / 9$ & 1 & 1 & 1 & 1 & 1 & 1 & 1 \\
\hline & Maybe & $2 / 9$ & 0 & 0 & 0 & 0 & 0 & 0 & 0 \\
\hline & No & $3 / 9$ & 0 & 0 & 0 & 0 & 0 & 0 & 0 \\
\hline \multirow{3}{*}{ Sensitivity $\left(p_{6}\right)$} & Null & 0 & 0 & 1 & 0 & 0 & 0 & 0 & 0 \\
\hline & Partial & $2 / 9$ & 0 & 0 & 1 & 1 & 1 & 1 & 0 \\
\hline & Total & $3 / 9$ & 1 & 0 & 0 & 0 & 0 & 0 & 1 \\
\hline
\end{tabular}




\subsection{Supporting the selection of project alternatives}

Several technologies have been developed to treat sanitary sewage, accelerating the process of degradation and stabilization. Although destined to control pollution, sewage treatment plants (STP) are also environment-modifying activities, capable of causing environmental impacts.

To evaluate the performance of the $i g i_{w}$ in the selection of the more appropriate project, three siting and three alternative technologies, totalling nine project alternatives for installation of a STP of medium-sized into an urban condominium, were comparatively analysed.

Considering the technological variability applicable to sewage treatment processes, in the selection of the alternatives for comparative purposes were considered the ones most commonly used in the region:

(1) Wastewater Stabilization Lagoon - WSL, treatment by microorganisms through anaerobic fermentation, aerobic oxidation and photosynthetic reduction by algae;

(2) Activated Sludge Process - ASP, treatment by high concentration, suspension and microbial recirculation through aerobic oxidation with the use of mechanized aerators;

(3) Up flow Anaerobic Sludge Blanket - UASB, treatment by microorganisms through anaerobic fermentation in closed compartment.

These alternatives were scored by experts with regard to the potential environmental impacts, resulting in Tables 8 and 9, as the tabular form of three-dimensional matrices $\mathbf{M}_{i \lambda \tau}$ (magnitude) and $\mathbf{I}_{i \lambda \tau}$ (importance). Then, the application of eqn (19) results in:

$$
\begin{aligned}
& \boldsymbol{I G I}_{\boldsymbol{w}}=\left[\mathrm{igi}_{w_{11}} \mathrm{igi}_{w_{12}} \mathrm{igi}_{w_{13}} \mathrm{igi}_{w_{21}} \mathrm{igi}_{w_{22}} \mathrm{igi}_{w_{23}} \mathrm{igi}_{w_{31}} \mathrm{igi}_{w_{32}} \mathrm{igi}_{w_{33}}\right] \text {, }
\end{aligned}
$$

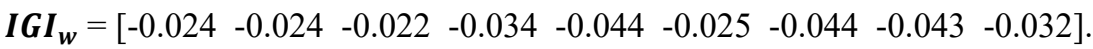

In turn, from the eqn (20), the best project alternatives correspond to:

$$
A_{\lambda^{\prime} \tau^{\prime}}=\max \left(\boldsymbol{I} \boldsymbol{G I}_{\boldsymbol{w}}\right)=\left[\operatorname{igi}_{w_{13}}\right]=[-0.022]=A_{13},
$$

i.e. the $\operatorname{UASB}\left(\tau_{3}\right)$ at northwest sector $\left(\lambda_{1}\right)$.

\section{CONCLUSIONS}

From the results, it can be concluded that the $i g i_{w}$ provides a promising approach that allows supporting decision-making by experts, for both applications presented in this paper, i.e. to a comparative evaluation among the maintenance and demolishing scenarios of irregular activities, and to select project alternatives, prior to the implementation of new activities.

In the first application, the $i g i_{w}$ showed be appropriated for analyzes case-by-case, involving complex issues as a maintenance of irregular activities, when it is less prejudicial than its demolishing. In turn, in the second case, the impact global index pointed out that the best solution is not necessarily unique. Therefore, the outcomes indicate a satisfactory performance of the integrated analyses by means of a single value provided by the $i g i_{w}$, and its potential for other applications.

For further progress, in future studies we will seek to improve the $i g i_{w}$ with usage of fuzzy modeling, in order to more appropriately address issues of subjectivity in the assessment of environmental impacts. 
Table 8: Analysis of the impacts with regard to the magnitude indicators $\left(\mathbf{M}_{i \lambda \tau}\right)$. (Source: Modified from Bressane et al. [4].)

\begin{tabular}{|c|c|c|c|c|c|c|c|c|c|c|c|c|c|c|c|c|c|c|c|c|}
\hline \multicolumn{3}{|c|}{ Parameters } & \multicolumn{17}{|c|}{ Environmental impacts } & \\
\hline$p_{j}$ & $m_{k j}$ & $w_{k j}$ & & $i_{I}$ & & $i_{2}$ & & $i_{3}$ & & & $i_{4}$ & & $i_{5}$ & & & $i_{6}$ & & $i_{7}$ & & \\
\hline \multirow{3}{*}{ 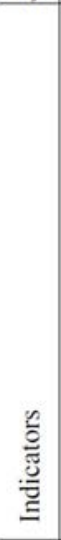 } & \multirow{3}{*}{ 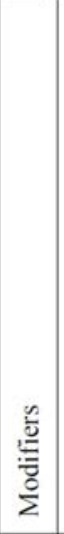 } & \multirow{3}{*}{$\begin{array}{l}\frac{z}{5} \\
\frac{.00}{0} \\
3\end{array}$} & \multicolumn{3}{|c|}{ 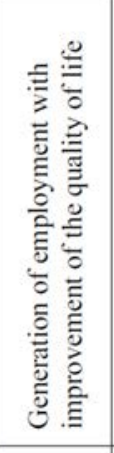 } & \multicolumn{2}{|c|}{ 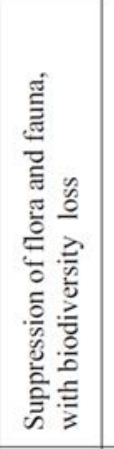 } & \multicolumn{2}{|c|}{ 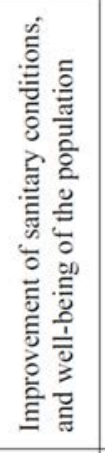 } & \multicolumn{3}{|c|}{ 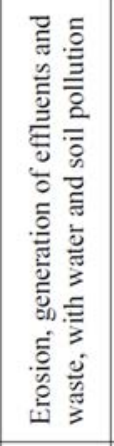 } & \multicolumn{2}{|c|}{ 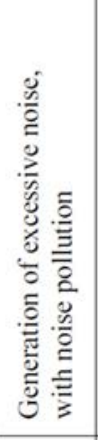 } & \multicolumn{2}{|c|}{ 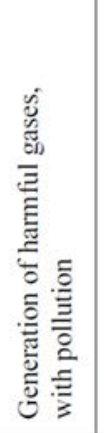 } & \multicolumn{3}{|c|}{ 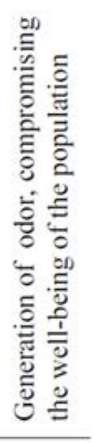 } & \\
\hline & & & \multicolumn{3}{|c|}{$\tau$} & \multicolumn{2}{|l|}{$\tau$} & \multicolumn{2}{|c|}{$\tau$} & \multicolumn{3}{|c|}{$\tau$} & \multicolumn{2}{|c|}{$\tau$} & \multicolumn{2}{|c|}{$\tau$} & \multicolumn{3}{|c|}{$\tau$} & \\
\hline & & & 1 & 2. & 3 & \begin{tabular}{l|l|}
1 & 2 \\
\end{tabular} & 3 & \begin{tabular}{l|l}
1 & 2 \\
\end{tabular} & 3 & 1 & 2 & 3 & & 3 & & \begin{tabular}{ll|}
2 & 3 \\
\end{tabular} & & 2. & & \\
\hline \multirow{9}{*}{ 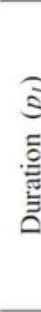 } & & & 0 & 0 & 0 & \begin{tabular}{l|l}
0 & 0
\end{tabular} & 0 & \begin{tabular}{l|l}
0 & 0 \\
\end{tabular} & 0 & 0 & 0 & 0 & \begin{tabular}{|l|l|}
0 & 0 \\
\end{tabular} & 0 & \begin{tabular}{l|l}
0 & 0 \\
\end{tabular} & \begin{tabular}{l|l|}
0 & 0 \\
\end{tabular} & 0 & 0 & & \\
\hline & $m_{11}$ & $1 / 9$ & 0 & 0 & 0 & $\begin{array}{ll}0 & 0\end{array}$ & 0 & \begin{tabular}{l|l}
0 & 0 \\
\end{tabular} & 0 & 0 & 0 & 0 & \begin{tabular}{ll|}
0 & 0 \\
\end{tabular} & 0 & $\begin{array}{ll}0 & 0 \\
\end{array}$ & $\begin{array}{ll}0 & 0 \\
\end{array}$ & & 0 & \begin{tabular}{l|l}
0 & 2 \\
\end{tabular} & $\lambda$ \\
\hline & & & 0 & 0 & 0 & $\begin{array}{ll}0 & 0 \\
\end{array}$ & 0 & \begin{tabular}{l|l}
0 & 0 \\
\end{tabular} & 0 & 0 & 0 & 0 & \begin{tabular}{|l|l|}
0 & 0 \\
\end{tabular} & 0 & $\begin{array}{ll}0 & 0 \\
\end{array}$ & $\begin{array}{ll}0 & 0 \\
\end{array}$ & & 0 & \begin{tabular}{l|l}
0 & 3 \\
\end{tabular} & \\
\hline & & & 0 & 0 & 0 & \begin{tabular}{l|l}
0 & 0
\end{tabular} & 0 & \begin{tabular}{l|l}
0 & 0 \\
\end{tabular} & 0 & 0 & 0 & 0 & \begin{tabular}{|l|l|}
0 & 0 \\
\end{tabular} & 0 & \begin{tabular}{|l|l|}
0 & 0 \\
\end{tabular} & \begin{tabular}{l|l|}
0 & 0
\end{tabular} & & 0 & \begin{tabular}{l|l}
0 & 1
\end{tabular} & \\
\hline & $m_{21}$ & $2 / 9$ & 0 & 0 & 0 & $\begin{array}{ll}0 & 0\end{array}$ & 0 & \begin{tabular}{l|l}
0 & 0 \\
\end{tabular} & 0 & 0 & 0 & 0 & $\begin{array}{ll}0 & 0\end{array}$ & 0 & $\begin{array}{ll}0 & 0 \\
\end{array}$ & $\begin{array}{ll}0 & 0 \\
\end{array}$ & & 0 & \begin{tabular}{l|l}
0 & 2
\end{tabular} & $\lambda$ \\
\hline & & & 0 & 0 & 0 & \begin{tabular}{l|l|}
0 & 0
\end{tabular} & 0 & \begin{tabular}{l|l}
0 & 0 \\
\end{tabular} & 0 & 0 & 0 & 0 & \begin{tabular}{|l|l|}
0 & 0 \\
\end{tabular} & 0 & \begin{tabular}{l|l}
0 & 0 \\
\end{tabular} & \begin{tabular}{l|l|}
0 & 0 \\
\end{tabular} & & 0 & \begin{tabular}{l|l}
0 & 3 \\
\end{tabular} & \\
\hline & & & 1 & 1 & 1 & $-1-1$ & $\mid-1$ & \begin{tabular}{l|l}
11 & 1 \\
\end{tabular} & 1 & -1 & -1 & -1 & \begin{tabular}{|c|c|} 
& -1 \\
\end{tabular} & -1 & $-1-1$ & \begin{tabular}{l|l|}
$1-1$ \\
\end{tabular} & & -1 & $\begin{array}{ll}-1 & 1 \\
\end{array}$ & \\
\hline & $m_{31}$ & $3 / 9$ & 1 & 1 & 1 & $-1 \mid-1$ & -1 & \begin{tabular}{l|l}
1 & 1 \\
\end{tabular} & 1 & -1 & -1 & -1 & \begin{tabular}{|l|l|}
-1 & -1 \\
\end{tabular} & -1 & $-1-1$ & $1-1$ & & -1. & \begin{tabular}{l|l}
-1 & 2
\end{tabular} & $\lambda$ \\
\hline & & & 1 & 1 & 1 & $-1 \quad-1$ & -1 & $\begin{array}{ll}1 & 1 \\
\end{array}$ & 1 & -1 & -1 & -1 & $-1 \quad-1$ & -1 & $-1 \quad-1$ & $1-1$ & & & -13 & \\
\hline & & & 0 & 0 & 0 . & $-1-1$ & -1 & \begin{tabular}{l|l}
0 & 0 \\
\end{tabular} & 0 & 0 & 0 & 0 & \begin{tabular}{|l|l|}
-1 & 0 \\
\end{tabular} & -1 & \begin{tabular}{l|l}
0 & 0 \\
\end{tabular} & \begin{tabular}{l|l|}
0 & 0 \\
\end{tabular} & & -1 & \begin{tabular}{l|l}
0 & 1
\end{tabular} & \\
\hline & $m_{12}$ & $1 / 9$ & 0 & 0 & 0 . & $-1-1$ & -1 & $\begin{array}{lll}0 & 0 \\
\end{array}$ & 0 & 0 & 0 & 0 & $\begin{array}{ll}-1 & 0 \\
\end{array}$ & -1 & $\begin{array}{ll}0 & 0 \\
\end{array}$ & $\begin{array}{lll}0 & 0 \\
\end{array}$ & & -1 & \begin{tabular}{l|l}
0 & 2 \\
\end{tabular} & $\lambda$ \\
\hline હิ & & & 0 & 0 & 0 . & $-1-1$ & -1 & \begin{tabular}{l|l}
0 & 0 \\
\end{tabular} & 0 & 0 & 0 & 0 & \begin{tabular}{|l|l|}
-1 & 0 \\
\end{tabular} & -1 & \begin{tabular}{l|l}
0 & 0 \\
\end{tabular} & \begin{tabular}{|l|l|}
0 & 0 \\
\end{tabular} & & -1 & \begin{tabular}{l|l}
0 & 3 \\
\end{tabular} & \\
\hline & & & 1 & 1 & 1 & \begin{tabular}{l|l}
0 & 0 \\
\end{tabular} & 0 & \begin{tabular}{l|l}
0 & 0 \\
\end{tabular} & 0 & 0 & 0 & 0 & $\begin{array}{lll}0 & -1 \\
\end{array}$ & 0 & \begin{tabular}{ll|l}
0 & 0 \\
\end{tabular} & \begin{tabular}{ll|}
0 & 0 \\
\end{tabular} & & 0 . & \begin{tabular}{l|l}
-1 & 1 \\
\end{tabular} & \\
\hline & $m_{22}$ & $2 / 9$ & 1 & 1 & 1 & \begin{tabular}{l|l|}
0 & 0
\end{tabular} & 0 & \begin{tabular}{l|l}
0 & 0 \\
\end{tabular} & 0 & 0 & 0 & 0 & \begin{tabular}{|l|l|}
0 & -1 \\
\end{tabular} & 0 & \begin{tabular}{l|l}
0 & 0
\end{tabular} & \begin{tabular}{|l|l|}
0 & 0 \\
\end{tabular} & -1 & 0 . & \begin{tabular}{l|l}
-1 & 2
\end{tabular} & $\lambda$ \\
\hline & & & 1 & 1 & 1 & \begin{tabular}{l|l|}
0 & 0 \\
\end{tabular} & 0 & \begin{tabular}{l|l}
0 & 0 \\
\end{tabular} & 0 & 0 & 0 & 0 & \begin{tabular}{|lll}
0 & -1 \\
\end{tabular} & 0 & $\begin{array}{lll}0 & 0\end{array}$ & \begin{tabular}{ll|}
0 & 0 \\
\end{tabular} & & 0 . & $\begin{array}{ll}-1 & 3\end{array}$ & \\
\hline & & & 0 & 0 & 0 & \begin{tabular}{l|l|}
0 & 0
\end{tabular} & \begin{tabular}{|l|l|} 
& \\
\end{tabular} & \begin{tabular}{l|l|}
1 & 1 \\
\end{tabular} & 1 & $\mid-1$ & -1 & -1 & \begin{tabular}{|l|l|}
0 & 0 \\
\end{tabular} & 0 & \begin{tabular}{|c|c|} 
& -1 \\
\end{tabular} & \begin{tabular}{ll|l|} 
& -1 \\
\end{tabular} & 0 & 0 & \begin{tabular}{l|l}
0 & 1 \\
\end{tabular} & \\
\hline & $m_{32}$ & $3 / 9$ & 0 & 0 & 0 & \begin{tabular}{l|l}
0 & 0
\end{tabular} & 0 & $\begin{array}{ll}1 & 1\end{array}$ & 1 & -1 & -1 & -1 & \begin{tabular}{ll|}
0 & 0
\end{tabular} & 0 & $\begin{array}{lll}-1 & -1 \\
\end{array}$ & \begin{tabular}{l|l|}
1 & -1 \\
\end{tabular} & & 0 & \begin{tabular}{l|l}
0 & 2 \\
\end{tabular} & $\lambda$ \\
\hline & & & 0 & 0 & 0 & \begin{tabular}{l|l|}
0 & 0 \\
\end{tabular} & 0 & \begin{tabular}{l|l|}
1 & 1 \\
\end{tabular} & 1 & -1 & -1 & -1 & \begin{tabular}{|l|l|}
0 & 0 \\
\end{tabular} & 0 & $\begin{array}{lll} & -1 \\
\end{array}$ & $\begin{array}{lll}1 & -1 \\
\end{array}$ & & 0 & \begin{tabular}{l|l}
0 & 3 \\
\end{tabular} & \\
\hline & & & 1 & 1 & 0 & \begin{tabular}{|c|c|}
-1 & -1
\end{tabular} & -1 & \begin{tabular}{l|l}
0 & 0 \\
\end{tabular} & 0 & -1 & 0 & -1 & \begin{tabular}{|l|l|}
-1 & 0 \\
\end{tabular} & -1 & \begin{tabular}{|l|l|l|}
0 & -1
\end{tabular} & $\begin{array}{ll}10 & 0\end{array}$ & & -1 & \begin{tabular}{l|l}
0 & 1 \\
\end{tabular} & \\
\hline & $m_{13}$ & $1 / 9$ & 0 & 0 & 0 & \begin{tabular}{l|l}
0 & 0
\end{tabular} & -1 & \begin{tabular}{l|l}
0 & 0 \\
\end{tabular} & 0 & -1 & 0 & -1 & $\begin{array}{ll}-1 & 0 \\
\end{array}$ & 0 & \begin{tabular}{|l|l|l|} 
& -1
\end{tabular} & 10 & 0 & -1 & \begin{tabular}{l|l}
0 & 2 \\
\end{tabular} & $\lambda$ \\
\hline & & & 0 & 0 & 0 & \begin{tabular}{l|l}
0 & 0 \\
\end{tabular} & -1 & \begin{tabular}{l|l}
0 & 0 \\
\end{tabular} & 0 & 0 & 0 & 0 & \begin{tabular}{|l|l|}
-1 & 0 \\
\end{tabular} & 0 & \begin{tabular}{|l|l|l|l|}
0 & -1
\end{tabular} & $\begin{array}{ll}1 & 0\end{array}$ & -1 & -1 & \begin{tabular}{l|l}
0 & 3 \\
\end{tabular} & \\
\hline & & & 0 & 0 & 1 & \begin{tabular}{|l|l|}
0 & 0
\end{tabular} & 0 & \begin{tabular}{l|l}
0 & 0 \\
\end{tabular} & 0 & 0 & -1 & 0 & $\begin{array}{lll}0 & -1\end{array}$ & 0 & -10 & \begin{tabular}{|l|l|}
0 & 0 \\
\end{tabular} & & 0 & \begin{tabular}{l|l}
0 & 1 \\
\end{tabular} & \\
\hline & $m_{23}$ & $2 / 9$ & 1 & 1 & 0 & \begin{tabular}{l|l|}
0 & -1
\end{tabular} & 0 & \begin{tabular}{l|l}
0 & 0 \\
\end{tabular} & 0 & 0 & 0 & 0 & \begin{tabular}{|l|l|}
0 & 0 \\
\end{tabular} & -1 & \begin{tabular}{l|l}
0 & 0 \\
\end{tabular} & \begin{tabular}{l|l|}
0 & -1 \\
\end{tabular} & & 0 & \begin{tabular}{l|l}
0 & 2
\end{tabular} & $\lambda$ \\
\hline & & & 1 & 1 & 0 & $\begin{array}{lll}0 & -1 \\
\end{array}$ & 0 & \begin{tabular}{l|l}
0 & 0 \\
\end{tabular} & 0 & -1 & 0 & -1 & $\begin{array}{ll}0 & 0 \\
\end{array}$ & -1 & \begin{tabular}{|l|l|l|}
-1 & 0 \\
\end{tabular} & \begin{tabular}{ll|}
0 & 0 \\
\end{tabular} & 0 & 0 . & $\begin{array}{ll}-13 \\
\end{array}$ & \\
\hline & & & 0 & \begin{tabular}{l|l}
0 \\
\end{tabular} & 0 & \begin{tabular}{|l|l|}
0 & 0 \\
\end{tabular} & \begin{tabular}{|l|l|} 
& \\
\end{tabular} & \begin{tabular}{l|l|}
1 & 1 \\
\end{tabular} & 1 & 0 & 0 & 0 & \begin{tabular}{|l|l|}
0 & 0 \\
\end{tabular} & 0 & \begin{tabular}{|l|l}
0 & 0 \\
\end{tabular} & \begin{tabular}{|l|l|}
0 & -1 \\
\end{tabular} & & 0 . & \begin{tabular}{l|l}
-1 & 1 \\
\end{tabular} & \\
\hline & $m_{33}$ & $3 / 9$ & 0 & 0 & 1 & $\begin{array}{ll}-1 & 0\end{array}$ & 0 & \begin{tabular}{l|l}
1 & 1 \\
\end{tabular} & 1 & 0 & -1 & 0 & \begin{tabular}{|l|l|}
0 & -1 \\
\end{tabular} & 0 & $\begin{array}{lll}0 & 0 \\
\end{array}$ & \begin{tabular}{ll|}
0 & 0 \\
\end{tabular} & & 0 . & \begin{tabular}{l|l}
-1 & 2 \\
\end{tabular} & $\lambda$ \\
\hline & & & 0 & 0 & 1 & \begin{tabular}{ll|}
-1 & 0
\end{tabular} & 0 & \begin{tabular}{l|l|}
1 & 1 \\
\end{tabular} & 1 & 0 & -1 & 0 & \begin{tabular}{|l|l|}
0 & -1 \\
\end{tabular} & 0 & \begin{tabular}{l|l}
0 & 0 \\
\end{tabular} & \begin{tabular}{l|l|}
0 & -1 \\
\end{tabular} & & 0 & \begin{tabular}{l|l}
0 & 3 \\
\end{tabular} & \\
\hline & & & 6 & 6 & 7 & \begin{tabular}{|c|c|}
5 & -5 \\
\end{tabular} & -5 & 99 & 9 & $\mid-7$ & -8 & -7 & \begin{tabular}{|l|l|l|}
-15 & -7 \\
\end{tabular} & -5 & \begin{tabular}{|l|l|l} 
& -7
\end{tabular} & $\begin{array}{c}-7 \\
\end{array}$ & & -5 & \begin{tabular}{l|l}
-8 & 1
\end{tabular} & \\
\hline & $\mathbf{M}_{i \lambda \tau}$ & & 7 & 7 & 8. & $\begin{array}{l}-7-6 \\
\end{array}$ & & 99 & 9 & & -9 & -7 & $\begin{array}{lll}-5 & -8 \\
\end{array}$ & -6 & & $\begin{array}{l}-7 \\
\end{array}$ & & & $\begin{array}{ll}-82 \\
\end{array}$ & $\lambda$ \\
\hline & & & 7 & 7 & 8. & \begin{tabular}{l|l|}
7 & -6 \\
\end{tabular} & $|-5|$ & \begin{tabular}{l|l}
9 & 9 \\
\end{tabular} & 9 & & -9 & & \begin{tabular}{|l|l|}
-5 & -8 \\
\end{tabular} & & & $7-9$ & & & \begin{tabular}{l|l}
-7 & 3 \\
\end{tabular} & \\
\hline & : short & it to $n$ & & & & $m_{12}:$ & pun & nc & & & $n_{13}:$ & & & & 1. WS & & & & rorth & \\
\hline & & 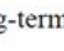 & & & & $m_{22}$ : & loc: & & & & $n_{23}$ : & me & lium & & $2: \mathrm{AS}$ & & & & & \\
\hline & perm & nane & & & & $m_{32}$ : & reg & & & & $n_{33}:$ & & & & ${ }_{3}: \mathrm{UA}$ & ASB & & : Sc & outh & \\
\hline
\end{tabular}


Table 9: Analysis of the impacts with regard to the importance indicators $\left(\mathbf{I}_{i \lambda \tau}\right)$. (Source: Modified from Bressane et al. [4].)

\begin{tabular}{|c|c|c|c|c|c|c|c|c|c|c|c|c|c|c|c|c|c|c|c|c|}
\hline \multicolumn{3}{|c|}{ Parameters } & \multicolumn{17}{|c|}{ Environmental impacts } & \\
\hline$p_{j}$ & $m_{k j}$ & $w_{k j}$ & & $i_{l}$ & & $i_{2}$ & & $i$ & & & $i_{4}$ & & & $i_{5}$ & & $i_{6}$ & & $i_{7}$ & & \\
\hline \multirow{3}{*}{ 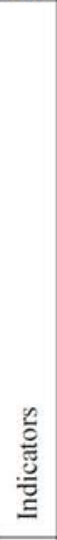 } & \multirow{3}{*}{ 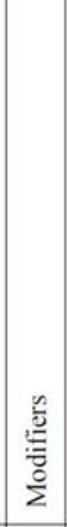 } & \multirow{3}{*}{$\begin{array}{l}\frac{\vec{c}}{00} \\
\frac{00}{2} \\
\geq\end{array}$} & \multicolumn{2}{|c|}{ 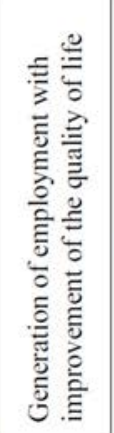 } & \multicolumn{3}{|c|}{ 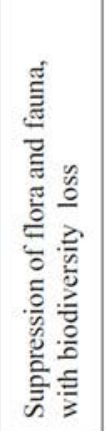 } & \multicolumn{3}{|c|}{ 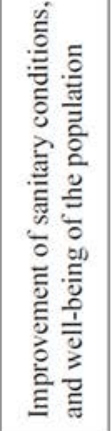 } & \multicolumn{2}{|c|}{ 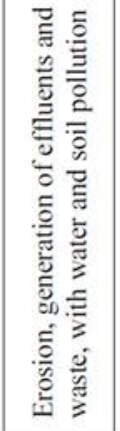 } & \multicolumn{2}{|c|}{ 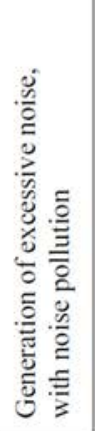 } & \multicolumn{3}{|c|}{ 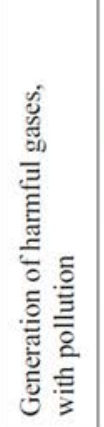 } & \multicolumn{3}{|c|}{ 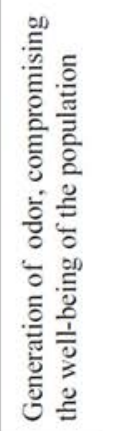 } \\
\hline & & & \multicolumn{2}{|r|}{$\tau$} & \multicolumn{3}{|c|}{$\tau$} & \multicolumn{3}{|c|}{$\tau$} & \multicolumn{2}{|l|}{$\tau$} & \multicolumn{2}{|r|}{$\tau$} & \multicolumn{3}{|c|}{$\tau$} & \multicolumn{3}{|c|}{$\tau$} \\
\hline & & & 1 & \begin{tabular}{l|l}
2 & 3 \\
\end{tabular} & 1 & 2 & 3 & 12 & 2. & 3 & 2 & 3 & 1 & \begin{tabular}{l|l}
2 & 3 \\
\end{tabular} & 1 & 2 & 3. & & 3 & \\
\hline \multirow{9}{*}{ 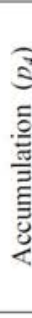 } & & & 0 & \begin{tabular}{l|l}
0 & 0 \\
\end{tabular} & 1 & 1 & 1 & $\begin{array}{ll}0 & 0 \\
0\end{array}$ & 50 & 0 & 0 & 0 & 0 & \begin{tabular}{l|l}
0 & 0 \\
\end{tabular} & 0 & 0 & 0 ( 0 & \begin{tabular}{l|l}
0 & 1 \\
\end{tabular} & 0 & \\
\hline & $m_{44}$ & $1 / 9$ & 0 & 0 & 0 & 0 & 0 & 00 & ( & 1 & 0 & 1 & 1 & $\begin{array}{ll}0 & 0 \\
\end{array}$ & 0 & 0 & 0 & $\begin{array}{lll}0 & 1\end{array}$ & 0 & \\
\hline & & & 0 & 0 & 0 & 0 & 0 & 0 & ( & 0 & 0 & 0 & 1 & \begin{tabular}{l|l}
0 & 0 \\
\end{tabular} & 0 & 0 & 0 & $\begin{array}{lll}0 & 1 \\
\end{array}$ & 0 & 3 \\
\hline & & & 1 & 1 & 0 & 0 & 0 & 0 & ( & 1 & 0 & 1 & 0 & 00 & 0 & 0 & 0 & $\begin{array}{lll}0 & 0\end{array}$ & 0 & 1 \\
\hline & $m_{54}$ & $2 / 9$ & 1 & 1 & 1 & 0 & 0 & 00 & ( & 0 & 0 & 0 & 0 & $\begin{array}{lll}0 & 1\end{array}$ & 1 & 1 & 1 & 10 & 1 & 2 \\
\hline & & & 1 & 1 & 1 & 1 & 1 & 00 & ( & 1 & 0 & 1 & 0 & $\begin{array}{ll}0 & 1\end{array}$ & 1 & 1 & 1 & 10 & 1 & 3 \\
\hline & & & 0 & 0 & 0 & 0 & \begin{tabular}{l|l}
0 \\
\end{tabular} & \begin{tabular}{l|l}
1 & 1 \\
\end{tabular} & 1 & 10 & 1 & \begin{tabular}{l|l}
0 \\
\end{tabular} & \begin{tabular}{|l|} 
\\
\end{tabular} & \begin{tabular}{l|l}
11 & 1
\end{tabular} & 1 & 1 & 1 & \begin{tabular}{l|l}
1 & 0
\end{tabular} & 1 & 1 \\
\hline & $m_{64}$ & $3 / 9$ & 0 & 0 & 0 & 1 & 1 & 1 & 1 & 10 & 1 & 0 & 0 & 10 & 0 & 0 & 0 & $\begin{array}{lll}0 & 0\end{array}$ & 0 & 2 \\
\hline & & & 0 & 0 & 0 & 0 & 0 & 1 & 1 & 0 & 1 & 0 & 0 & \begin{tabular}{l|l}
10 \\
\end{tabular} & 0 & 0 & $\begin{array}{ll}0 \\
0\end{array}$ & $\begin{array}{ll}0 & 0\end{array}$ & 0 & 3 \\
\hline & & & 0 & 0 & 0 & 0 & $\begin{array}{ll}0 \\
\end{array}$ & \begin{tabular}{l|l}
0 & 0
\end{tabular} & 8 & 0 & 0 & 0 & 0 & \begin{tabular}{l|l}
0 & 0
\end{tabular} & 0 & 0 & \begin{tabular}{|l|l|} 
& \\
\end{tabular} & \begin{tabular}{l|l}
0 & 0
\end{tabular} & 0 & 1 \\
\hline & $m_{45}$ & $1 / 9$ & 0 & 0 & 0 & 0 & 0 & $\begin{array}{lll}0 & 0\end{array}$ & ( & 0 & 0 & 0 & 0 & \begin{tabular}{l|l}
0 & 0
\end{tabular} & 0 & 0 & 0 & $\begin{array}{lll}0 & 0\end{array}$ & 0 & 2 \\
\hline 3 & & & 0 & \begin{tabular}{l|l}
0 & 0
\end{tabular} & 0 & 0 & $\begin{array}{ll}0 \\
\end{array}$ & \begin{tabular}{l|l}
0 & 0
\end{tabular} & ( & 0 & 0 & 0 & 0 & \begin{tabular}{l|l}
0 & 0
\end{tabular} & 0 & 0 & 0 & $\begin{array}{ll}0 & 0\end{array}$ & 0 & 3 \\
\hline & & & 1 & 1 & 0 & 0 & 0 & \begin{tabular}{l|l}
1 & 1
\end{tabular} & 1 & 1 & 1 & 1 & 1 & 11 & 1 & 1 & 1 & $\begin{array}{ll}1 & 1\end{array}$ & 1 & 1 \\
\hline & $m_{55}$ & $2 / 9$ & 1 & 1 & 0 & 0 & 0 & 1 & 1 & 11 & 1 & 1 & 1 & \begin{tabular}{l|l}
1 & 1
\end{tabular} & 1 & 1 & 1 & $\begin{array}{lll}1 & 1\end{array}$ & 1 & 2 \\
\hline & & & 1 & 1 & 0 & 0 & 0 & \begin{tabular}{l|l}
1 & 1
\end{tabular} & 1 & 11 & 1 & 1 & 1 & \begin{tabular}{l|l}
1 & 1
\end{tabular} & 1 & 1 & 1 & \begin{tabular}{l|l}
1 & 1
\end{tabular} & 1 & 3 \\
\hline & & & 0 & 0 & 1 & 1 & 1 & \begin{tabular}{l|l}
0 & 0
\end{tabular} & ( & 0 & 0 & \begin{tabular}{l|l}
0 \\
\end{tabular} & \begin{tabular}{|l|l|} 
\\
\end{tabular} & \begin{tabular}{l|l}
0 & 0
\end{tabular} & 0 & 0 & \begin{tabular}{|l|l} 
\\
\end{tabular} & \begin{tabular}{l|l}
0 & 0
\end{tabular} & 0 & 1 \\
\hline & $m_{65}$ & $3 / 9$ & 0 & 0 & 1 & 1 & 1 & 00 & ( & 0 & 0 & 0 & 0 & \begin{tabular}{l|l}
0 & 0
\end{tabular} & 0 & 0 & 0 & $\begin{array}{lll}0 & 0\end{array}$ & 0 & 2 \\
\hline & & & 0 & 0 & 1 & 1 & 1 & $\begin{array}{lll}0 & 0\end{array}$ & ( & 0 & 0 & 0 & 0 & \begin{tabular}{l|l}
0 & 0
\end{tabular} & 0 & 0 & 0 & \begin{tabular}{l|l}
0 & 0
\end{tabular} & 0 & 3 \\
\hline & & & 1 & 1 & 1 & 1 & 1 & $\begin{array}{lll}0 & 0\end{array}$ & 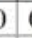 & 0 & 0 & 0 & 0 & \begin{tabular}{l|l}
0 & 0
\end{tabular} & 0 & 0 & 0 & \begin{tabular}{l|l}
0 & 1
\end{tabular} & 0 & 1 \\
\hline & $m_{46}$ & 0 & 1 & 1 & 0 & 0 & 0 & $\begin{array}{lll}0 & 0\end{array}$ & 8 & 0 & 0 & 0 & 0 & $\begin{array}{lll}0 & 0\end{array}$ & 0 & 0 & 0 & $\begin{array}{lll}0 & 1\end{array}$ & 0 & 2 \\
\hline $3^{\circ}$ & & & 1 & 1 & 0 & 0 & 0 & \begin{tabular}{l|l}
1 & 1
\end{tabular} & L & 10 & 0 & 0 & 1 & 11 & 0 & 0 & 0 & $\begin{array}{lll}1 & 1\end{array}$ & 1 & 3 \\
\hline & & & 0 & 0 & 0 & 0 & 0 & $\begin{array}{lll}0 & 0\end{array}$ & 1 & 1 & 1 & 1 & 0 & \begin{tabular}{l|l}
0 & 0
\end{tabular} & 0 & 0 & 0 & $\begin{array}{ll}10 \\
1\end{array}$ & 1 & 1 \\
\hline & $m_{56}$ & $2 / 9$ & 0 & 0 & 0 & 0 & 1 & $\begin{array}{lll}1 & 1\end{array}$ & 1 & 11 & 1 & 1 & 0 & $\begin{array}{lll}1 & 1\end{array}$ & 1 & 1 & 1 & $\begin{array}{lll}0 & 0\end{array}$ & 0 & \\
\hline & & & 0 & 0 & 0 & 1 & 1 & \begin{tabular}{l|l}
0 & 0
\end{tabular} & 1 & 0 & 0 & 0 & 0 & \begin{tabular}{l|l}
0 & 0
\end{tabular} & 1 & 1 & 1 & $\begin{array}{lll}0 & 0\end{array}$ & 0 & 3 \\
\hline & & & 0 & 0 & 0 & 0 & 0 & $\begin{array}{lll}1 & 1\end{array}$ & 1 & 10 & 0 & 0 & 1 & 11 & 1 & 1 & 1 & $\begin{array}{lll}0 & 0\end{array}$ & 0 & 1 \\
\hline & $m_{66}$ & $3 / 9$ & 0 & 0 & 1 & 1 & 0 & \begin{tabular}{l|l}
0 & 0 \\
\end{tabular} & 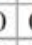 & 0 & 0 & 0 & 1 & \begin{tabular}{l|l}
0 & 0
\end{tabular} & 0 & 0 & 0 & \begin{tabular}{l|l}
10 \\
1
\end{tabular} & 1 & t \\
\hline & & & 0 & 0 & 1 & 0 & 0 & 0 & ( & 1 & 1 & 1 & 0 & \begin{tabular}{l|l}
0 & 0 \\
\end{tabular} & 0 & 0 & 0 & $\begin{array}{lll}0 & 0\end{array}$ & 0 & 3 \\
\hline & & & 4 & 4 & 3 & 3 & 3 & \begin{tabular}{l|l}
88 \\
\end{tabular} & 3 & 36 & 7 & \begin{tabular}{l|}
6 \\
\end{tabular} & 8 & \begin{tabular}{l|l}
8 & 8
\end{tabular} & 8 & 8 & \begin{tabular}{|l|}
8 \\
\end{tabular} & $\begin{array}{ll}7 & 2\end{array}$ & 7 & 1 \\
\hline & $9 \mathbf{I}_{i \lambda \tau}$ & & 4 & 47 & 8 & 9 & 8 & 77 & 7 & 74 & 7 & 4 & 5 & 76 & 6 & 6 & 6 & $\begin{array}{ll}7 & 2\end{array}$ & 7 & 2 \\
\hline & & & 4 & $\begin{array}{ll}47 \\
\end{array}$ & 8 & 7 & 7 & \begin{tabular}{l|l}
5 & 5
\end{tabular} & & & 8 & 7 & 2 & \begin{tabular}{l|l}
5 & 4
\end{tabular} & & 6 & 6 & $\begin{array}{lll}4 & 2 \\
\end{array}$ & 4 & 3 \\
\hline & $44:$ abs & & & & & & & & & & & & & & & & $\pi$ & hwes & & \\
\hline & 54: unc & certai & & $m_{55}$ & & ay & & & & & & & As & & & & & & & \\
\hline & ${ }_{64}: \mathrm{pr}$ & sent & & $m_{65}$ & & & & & & & & & It & ASB & & $t_{3}: \mathrm{S}$ & & & & \\
\hline
\end{tabular}




\section{REFERENCES}

[1] Canter, L.W., Environmental Impact Assessment, McGraw-Hill: New York, 1994.

[2] ENVLW, The Impact of Environmental Assessment: The World Bank's Experience, World Bank: Washington, 1996.

[3] Bressane, A., Reis, F.A.G.V., Giordano, L.C., Roveda, S.R.M.M., Martins, A.C.G. \& Roveda, J.A.F., Construction of an impact global index for comparative environmental analysis applied to the settlement of irregular activities. Revista Engenharia Sanitária e Ambiental, 22(1), pp. 111-122, 2017. (In Portuguese.)

[4] Bressane, A., Roveda, J.A.F., Roveda, S.R.M.M., Martins, A.C.G., Reis, F.A.G.V. \& Giordano, L.C., PROJECT Alternatives selection using an environmental impact global index. Revista Geociências, 37(1), pp. 155-166, 2018. (In Portuguese.)

[5] Rocha, G. (ed.), Map of Groundwater of the State of São Paulo, DAEE: São Paulo, 2005.

[6] Monteiro, C.A.F., Climatic Dynamics and Rainfall in the São Paulo State, USP: São Paulo, 1973. (In Portuguese.)

[7] Braga, A., Flow Criteria, PUC: Rio de Janeiro, 2010. (In Portuguese.)

[8] Ross, J.L.S. \& Moroz, I.C., Geomorphological Map of the State of São Paulo, IPT: São Paulo, 1997.

[9] Oliveira, J.B., Camargo, M.N., Rossi, M. \& Calderano Filho, B., Pedological Map of the State of São Paulo, EMBRAPA: Campinas, 1999.

[10] Kronka, F.J.N. et al. Forest Inventory of Natural Vegetation of São Paulo State, Instituto Florestal: São Paulo, 2005. (In Portuguese.)

[11] Saaty, T.L., Decision making with the analytic hierarchy process. Int. J. Services Sciences, 1(1), pp. 83-98, 2008. 